\title{
Mechanical Characterization of GPL/Polymer Nanocomposite Structure using Finite Element Analysis and SCILAB
}

\author{
Dilip Kumar Bagal ${ }^{*}$, Mousumee Ray ${ }^{2}$, Sandeep Bhoi ${ }^{3}$ \\ 1, ${ }^{2}$ Department of Mechanical Engineering, Government College of Engineering, Kalahandi, Bhawanipatna, Odisha, 766002, India . \\ 2, Department of Mechanical Engineering, Centre for Advanced Post Graduate Studies, BPUT, Rourkela, Odisha, 769015, India. \\ ${ }^{3}$ Assistant Professor, Dept. of Mechanical Engg., Parala Maharaja Engineering College (P.M.E.C), Berhampur, Odisha, 761003, India.
}

\begin{abstract}
Recent advances show that the Graphene platelets have dominated carbon nanotubes in the field of structural applications. This study is based on finding the mechanical properties and stress analysis of Graphene platelets. Here, the change in mechanical properties of epoxy nanocomposite with Graphene platelets at nano-fillers volume fraction of 0-0.112 was found. The mechanical properties measured were elastic modulus, shear modulus and bulk modulus by using SCILAB. The result shows that elastic modulus was increased $\sim 40 \%$, shear modulus and bulk modulus of the composite was increased $\sim 34 \%$. The properties so obtained were analyzed by using ANSYS 15.0. A cylindrical shell panel was designed for the purpose of this analysis. Mechanical properties at different volume fractions were studied for two different loading conditions. The results obtained from this analysis indicate that the stress value remains constant for both loading conditions and the deformation value decreases very rapidly.
\end{abstract}

Keywords: Graphene Platelets, Nanocomposite, ANSYS, SCILAB

\section{INTRODUCTION}

The transition of nano particles from micro particles changes drastically the physical properties. Since nanoscale materials have large surface area per unit volume, its properties vary substantially from that of the larger dimensional material's properties of same composition. The surface area per unit volume is inversely proportional to the material's/fiber diameter. Thus in case of particle or fiber smaller the diameter, greater the surface area per unit volume. For the fiber and layered material, the surface area/volume is dominated, especially for nonmaterial. Therefore, a change in particle diameter, layer thickness, or fibrous material diameter from the micrometer to nanometer range, will affect the surface area-to-volume ratio by three orders of magnitude [1]. Though a large study shows the fabrication of Graphene Platelets (GPL) in polymer matrix and manufacturing of GPL in different ways but studies have uncovered the static analysis of such composites.

In the present study a very small volume fraction of Graphene fillers is considered, of about a range of $0-0.112$ vol. \% in an epoxy matrix and the composite is fabricated. After the fabrication the different mechanical properties of the composite was found for different volume fraction of
Graphene platelets by using Halpin-Tsai Equation. As a first step graphs were plotted by varying the volume fraction of Graphene against the various mechanical properties by using SCILAB to get different mechanical properties. In the second step a shell panel is designed using ANSYS, having two conditions i.e. panel being fixed at one end and carries load at the other end and panel being fixed at both the ends and carrying uniformly distributed load all over it. In the last step static analysis of the shell panel is done for the above stated two conditions at different mechanical properties.

\section{METHODOLOGY}

Here, very small volume of Graphene platelets as filler material is used for study. Such GPLs in the epoxy polymer matrix provides a very large surface area per unit volume. The surface area per unit volume is inversely proportional to the material's/fiber diameter. Thus in case of particle or fiber smaller the diameter, greater the surface area per unit volume. Hence a low percentage of Graphene not only shows superior mechanical and thermal qualities than carbon nanotubes but also have capability to construct a variety of carbon based nano structures. Polymer based composites having Graphene as filler material has wide application in aerospace components, automobile industry, sporting goods. Moreover, with the use of low Graphene content the properties exhibited by it are not hampered.

Table 1: Material properties of epoxy

\begin{tabular}{|l|l|}
\hline Thermal stability & $315^{\circ} \mathrm{C}$ at $5 \%$ wt loss \\
\hline Thermal conductivity & $0.3 \mathrm{~W} / \mathrm{mK}$ \\
\hline Glass Transition Temperature & $210^{\circ} \mathrm{c}$ \\
\hline Young's modulus & $2.0 \mathrm{GPa}$ \\
\hline Tensile strength & $60 \mathrm{MPa}$ \\
\hline
\end{tabular}

Table 2: Material properties of GPL used

\begin{tabular}{|l|l|}
\hline Length $(\mathrm{L})$ & $2.5 \mu \mathrm{m}$ \\
\hline Width $(\mathrm{w})$ & $1.5 \mu \mathrm{m}$ \\
\hline Thickness $(\mathrm{t})$ & $1.5 \mathrm{~nm}$ \\
\hline Inter layer spacing $\left(\mathrm{t}^{\prime}\right)$ & $0.34 \mathrm{~nm}$ \\
\hline Young's modulus $\left(\mathrm{E}_{\mathrm{GPL}}\right)$ & $2.5 \mathrm{GPa}$ \\
\hline Density $(\rho)$ & $1.06 \mathrm{~g} / \mathrm{cm}^{3}$ \\
\hline
\end{tabular}




\subsection{Determination of composite properties}

Halpin-Tsai Hill equation is a micromechanical study of composite which is used to determine different properties of composite material. The Halpin-Tsai model for fiber reinforced composites was utilized to predict the Young's modulus of the nanocomposites. The Halpin-Tsai equation for GPL is given as follows:

$$
\begin{aligned}
E C= & \frac{3}{8} \times \frac{1+\left(\frac{L+W}{t}\right)\left[\frac{\left(\frac{E_{G P L}}{E m}\right)-1}{\left.\left(\frac{E_{G P L}}{E m}\right)+\frac{L+W}{t}\right]}\right] \times V_{G P L}}{1-\left[\frac{\left(\frac{E_{G P L}}{E m}\right)-1}{\left(\frac{E_{G P L}}{E m}\right)+\frac{L+W}{t}}\right] \times V_{G P L}} \times E m+\frac{5}{8} \times \\
& \frac{1+2\left[\frac{\left(\frac{E e f f}{E m}\right)-1}{\left(\frac{E e f f}{E m}\right)+2}\right] \times V_{G P L}}{1-\left[\frac{\left(\frac{E e f f}{E m}\right)-1}{\left(\frac{E e f f}{E m}\right)+2}\right] \times V_{G P L}} \times E m
\end{aligned}
$$

Where,

L- Average length of graphene fibers $\left(2.5 \times 10^{-3}-2.5 \times 10^{-5} \mathrm{~m}\right)$

$\mathrm{W}$ - Average width of graphene fibers $\left(1.5 \times 10^{-6} \mathrm{~m}\right)$

$\mathrm{t}$ - Average thickness of graphene fibers $\left(1.5 \times 10^{-9} \mathrm{~m}\right)$

$\mathrm{E}_{\mathrm{c}}$-Elastic modulus of composite

$\mathrm{E}_{\mathrm{m}}$ - Elastic modulus of matrix $\left(2.63 \times 10^{9} \mathrm{~Pa}\right)$

$\mathrm{E}_{\mathrm{GPL}}$ - Elastic modulus of graphene platelets $\left(2.5 \times 10^{12} \mathrm{~Pa}\right)$

$\left(\mathrm{E}_{\text {eff }}\right)-$ Effective elastic modulus of the fiber $\left(1.01 \times 10^{12} \mathrm{~Pa}\right)$

$\mathrm{V}_{\mathrm{GPL}}$ - Volume fraction of graphene platelets (0-0.112)

$\mathrm{V}_{\mathrm{m}}$ - Volume fraction of matrix

From the above equation the value of the composite material can be found out. Further the values of $K$ and $G$ were found by using following formulas:

$$
\mathrm{E}=2 \mathrm{G}\left(1+\mathrm{v}_{\mathrm{GPL}}\right), \mathrm{E}=3 \mathrm{~K}\left(1-2 \mathrm{v}_{\mathrm{GPL}}\right)
$$

To evaluate physical properties of composites, simple rule of mixture can be applied successfully as follows:

Density of the composite $\rho_{\mathrm{c}}=\rho_{\mathrm{m}} \times \mathrm{V}_{\mathrm{m}}+\rho_{\mathrm{f}} \times \mathrm{V}_{\mathrm{f}}$

Tensile strength of the composite: $\sigma_{\mathrm{c}}=\sigma_{\mathrm{m}} \times \mathrm{V}_{\mathrm{m}}+\sigma_{\mathrm{f}} \times \mathrm{V}_{\mathrm{f}}$.

Elastic modulus of the composite: $\mathrm{E}_{\mathrm{c}}=\mathrm{E}_{\mathrm{m}} \times \mathrm{V}_{\mathrm{m}}+\mathrm{E}_{\mathrm{f}} \times \mathrm{V}_{\mathrm{f}}$

Where: $\mathrm{V}_{\mathrm{f}}+\mathrm{V}_{\mathrm{m}}=1$

The density of the GPL and epoxy should be known in order to convert weight fraction to volume fraction, required to predict the elastic properties. For fibrous composites, the fiber volume fraction can be calculated using the density of the constituents:

$V_{G P L}=\frac{\rho_{\mathrm{C}}}{\rho_{\mathrm{GPL}}} \mathrm{W}_{\mathrm{GPL}} ; \rho_{\mathrm{C}}=\rho_{\mathrm{GPL}} \mathrm{V}_{\mathrm{GPL}}+\rho_{\mathrm{M}} \mathrm{V}_{\mathrm{M}}$
Rearranging equation (2) we can write in terms of $\mathrm{V}_{\mathrm{GPL}}$ :

$$
\mathrm{V}_{\mathrm{GPL}}=\frac{\mathrm{w}_{\mathrm{GPL}}}{\mathrm{w}_{\mathrm{GPL}}+\left(\rho_{\mathrm{GPL}} / \rho_{\mathrm{M}}\right)\left(1-\mathrm{W}_{\mathrm{GPL}}\right)}
$$

Where,

$$
\begin{aligned}
& v_{\mathrm{GPL}}=\text { Poisson's ratio of graphene platelets } \\
& \mathrm{V}_{\mathrm{f}}=\text { Volume fraction of fiber } \\
& \mathrm{W}_{\mathrm{GPL}}-\text { Weight fraction of graphene platelets }(0.1 \%) \\
& \rho_{\mathrm{c},} \rho_{\mathrm{m}}, \rho_{\mathrm{GPL}}=\text { Density of composite, matrix and graphene } \\
& \text { platelets respectively. } \\
& \rho_{\mathrm{m}}=1200 \mathrm{Kg} / \mathrm{m}^{3} \\
& \rho_{\mathrm{GPL}}=1060 \mathrm{Kg} / \mathrm{m}^{3}
\end{aligned}
$$

\subsection{Steps followed in Finite Element Analysis}

Step 1. The steps used in ANSYS for performing the stress analysis are as follows: In the very first step we have to select the preference for the study. There are so many fields available in ANSYS like thermal, fluid dynamics, structural design etc. As the present study is based on structural analysis, so preference is given as structural.

Step 2. In the second step we have to select the preprocessor. In this step element type, description of work and type of node is selected. For present work shell has been selected with 3D 4 node 181 .

Step 3. In this step the material properties are described under material model. For present work materials used are epoxy and GPL. The composite so formed is isotropic hence; Young's modulus and poisons ratio values were given which was obtained from SCILAB software.

Step 4. The next step is modeling of the composite. Modeling is a sub-option under preprocessor. The shell panel was modeled by drawing an arc of radius $100 \mathrm{~mm}$ by creating three key points. It was then given a rotation of $180^{\circ}$ and a thickness of $10 \mathrm{~mm}$ and the areas were plotted.

Step 5. In the last part of the second step meshing of the area is done by selecting the area mesh as shown in figure 3.6. The accuracy of the results depends of the meshing. The accuracy of the result depends upon the type of meshing.

Step 6. In the third step solution is done. To find the solution loading conditions are necessary. For the present work we consider two different types of loading conditions; that is:

i. Fixed at one end and carrying a load of $10 \mathrm{~N}$ in negative $\mathrm{x}$-direction.

ii. Fixed at both the ends and carrying a uniformly distributed load of $10 \mathrm{~N}$ in negative y-direction. 
International Journal of Applied Engineering Research ISSN 0973-4562 Volume 14, Number 1 (2019) pp. 69-78

(C) Research India Publications. https://dx.doi.org/10.37622/IJAER/14.1.2019.69-78

Step 7. The last and fourth step of the analysis is the General post processor. In this step results were plotted. The result plot shows both deformed and original shape of the shell panel for two different loading conditions.

Different results were plotted with the change of volume fraction of GPL. For this study the shell panel was divided with 126 numbers of nodes and 90 numbers of elements.

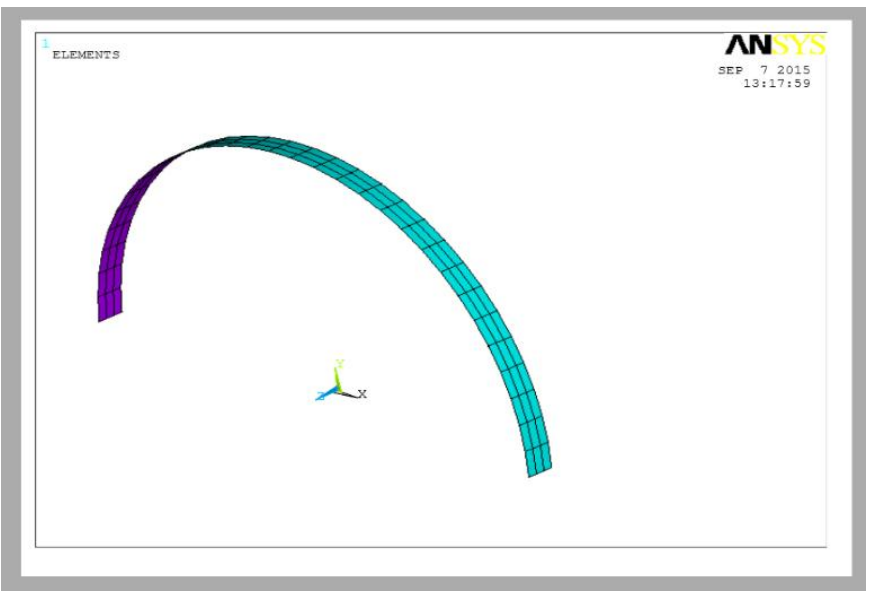

Fig. 1: Schematic representation of meshing done in the shell panel.

\section{RESULTS AND DISCUSSION}

\subsection{Determination of properties using SCILAB}

The properties of the GPL-based polymer nanocomposite were found by using SCILAB. Properties such as elastic modulus, shear modulus, bulk modulus and density of the composites were calculated for different volume fractions of GPL fillers.

A program was written in SCILAB in which following considerations were taken:

- Graphene platelets length was varied from $2.5 \times 10^{-3}$ to $2.5 \times 10^{-5}$.

- The volume fraction of GPL $\left(\mathrm{V}_{\mathrm{GPL}}\right)$ was taken in a range of $0-0.112$.

- $\quad \mathrm{V}_{\mathrm{GPL}}$ was taken in the $\mathrm{x}$-axis with an interval of 0.02 . Six divisions were observed from the range of 0-0.112.

- For each different volume fraction eleven values of different mechanical properties were found. A total of $11 \times 6$ values, each of elastic modulus, shear modulus, bulk modulus and density of the composite was found as result in the SCILAB.

- The properties were taken in y-axis and graphs were plotted for different properties.

- The results obtained from SCILAB are discussed and described below in the form of tables and graphs:
Table 3: Variation of $\mathrm{E}_{\mathrm{c}}$ with $\mathrm{V}_{\mathrm{GPL}}$

\begin{tabular}{|c|c|c|c|c|c|c|}
\hline $\mathrm{V}_{\mathrm{GPL}}$ & 0 & 0.02 & 0.04 & 0.06 & 0.08 & 0.1 \\
\hline \multirow{11}{*}{$\begin{array}{c}E_{c} \times 10^{10} \\
\left(N / m^{2}\right)\end{array}$} & 0.263 & 2.0523 & 3.845 & 5.643 & 7.4446 & 9.2504 \\
\hline & 0.263 & 2.1365 & 4.0108 & 5.886 & 7.762 & 9.6388 \\
\hline & 0.263 & 2.141 & 4.0196 & 5.8989 & 7.7788 & 9.6595 \\
\hline & 0.263 & 2.1426 & 4.0228 & 5.9035 & 7.7849 & 9.6669 \\
\hline & 0.263 & 2.1434 & 4.0244 & 5.9059 & 7.788 & 9.6707 \\
\hline & 0.263 & 2.1439 & 4.0254 & 5.9074 & 7.7899 & 9.673 \\
\hline & 0.263 & 2.1443 & 4.026 & 5.9083 & 7.7911 & 9.6745 \\
\hline & 0.263 & 2.1445 & 4.0265 & 5.909 & 7.7921 & 9.6766 \\
\hline & 0.263 & 2.1447 & 4.0269 & 5.9096 & 7.7927 & 9.6756 \\
\hline & 0.263 & 2.1449 & 4.0272 & 5.91 & 7.7933 & 9.6771 \\
\hline & 0.263 & 2.145 & 40.274 & 5.9103 & 7.7937 & 9.6777 \\
\hline
\end{tabular}

The table 3 shows that at 0 volume fraction the elastic modulus of composite is equal to the elastic modulus of epoxy matrix, because of complete absence of fibers. It was also observed that with increase in GPL content the elastic modulus increased from $2.63 \times 10^{9}$ to $9.2504 \times 10^{10}$ that is $\sim 40$ $\%$. The result so obtained show that with small increase in GPL volume the elasticity of composite is improved in a greater extent.

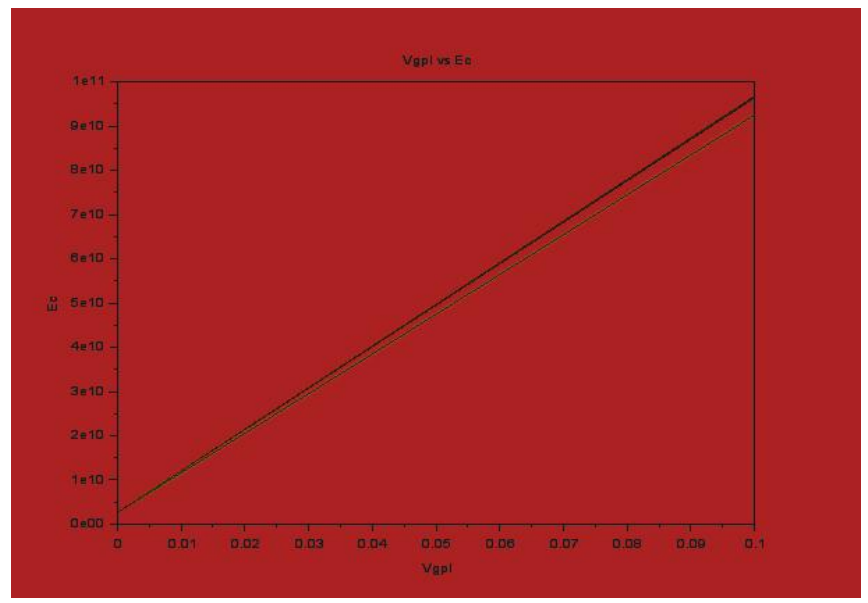

Fig. 2: Graph plotted between $E_{c}$ and $V_{G P L}$

The graph plotted between $\mathrm{E}_{\mathrm{c}}$ and $\mathrm{V}_{\mathrm{GPL}}$ show linear increase in elastic modulus for small increase in volume fraction of GPL. The graph starts with a value of $2.63 \times 10^{9}$ which depicts the absolute correctness of the graph. 
Table 4: Variation of $\mathrm{G}_{\mathrm{c}}$ with $\mathrm{V}_{\mathrm{GPL}}$

\begin{tabular}{|c|c|c|c|c|c|c|}
\hline $\mathrm{V}_{\mathrm{GPL}}$ & 0 & 0.02 & 0.04 & 0.06 & 0.08 & 0.1 \\
\hline \multirow{7}{*}{$\begin{array}{c}\mathrm{G}_{\mathrm{c}} \times 10^{10} \\
\left(\mathrm{~N} / \mathrm{m}^{2}\right)\end{array}$} & 0.09887 & 0.7715 & 1.4457 & 2.1215 & 2.7987 & 3.4776 \\
\cline { 2 - 7 } & 0.09887 & 0.8032 & 1.5078 & 2.2128 & 2.918 & 3.6236 \\
\cline { 2 - 7 } & 0.09887 & 0.80489 & 1.5111 & 2.2176 & 2.9244 & 3.6314 \\
\cline { 2 - 7 } & 0.09887 & 0.8055 & 1.5123 & 2.2194 & 2.9266 & 3.6342 \\
\cline { 2 - 7 } & 0.098877 & 0.8058 & 1.5129 & 2.2203 & 2.9278 & 3.6356 \\
\cline { 2 - 7 } & 0.09887 & 0.80612 & 1.5136 & 2.2212 & 2.929 & 3.637 \\
\cline { 2 - 7 } & 0.09887 & 0.80621 & 1.5137 & 2.2214 & 2.9293 & 3.6375 \\
\cline { 2 - 7 } & 0.09887 & 0.80628 & 1.5139 & 2.2216 & 2.9296 & 3.6378 \\
\cline { 2 - 7 } & 0.09887 & 0.80634 & 1.514 & 2.2218 & 2.9298 & 3.638 \\
\cline { 2 - 7 } & 0.09887 & 0.80638 & 1.5141 & 2.2219 & 2.93 & 3.6382 \\
\hline
\end{tabular}

The table 4 shows that at 0 volume fraction the shear modulus of composite is equal to the shear modulus of epoxy matrix, because of complete absence of fibers. It was also observed that with increase in GPL content the elastic modulus increased from $9.8872 \times 10^{8}$ at 0 to $3.4776 \times 10^{10}$ at 0.1 volume fraction which is $\sim 34 \%$. The result so obtained show that with small increase in GPL volume the rigidity of composite is improved.

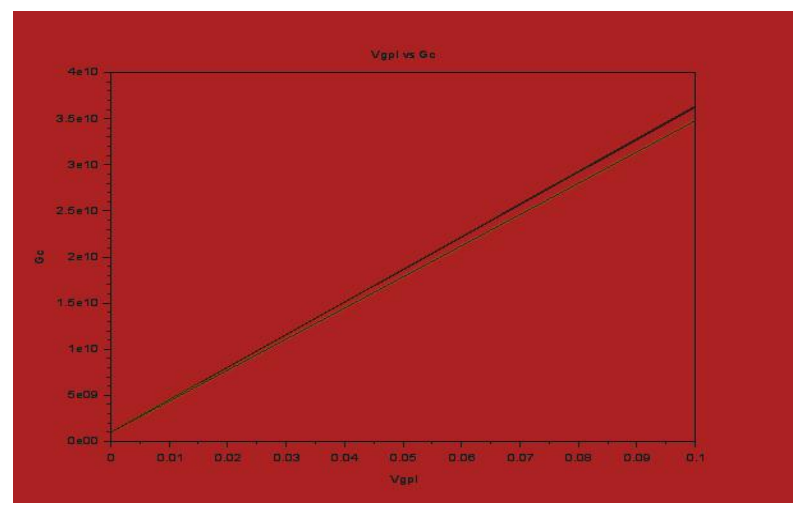

Fig. 3: Graph plotted between $\mathrm{G}_{\mathrm{c}}$ and $\mathrm{V}_{\mathrm{GPL}}$

The graph plotted between $\mathrm{G}_{\mathrm{c}}$ and $\mathrm{V}_{\mathrm{GPL}}$ show linear increase in shear modulus for small increase in volume fraction of GPL. The graph starts with a value of $9.8872 \times 10^{8}$ which depicts the absolute correctness of the graph.

Table 5: Variation of $\mathrm{K}_{\mathrm{c}}$ with $\mathrm{V}_{\mathrm{GPL}}$

\begin{tabular}{|c|c|c|c|c|c|c|}
\hline $\mathrm{V}_{\mathrm{GPL}}$ & 0 & 0.02 & 0.04 & 0.06 & 0.08 & 0.1 \\
\hline \multirow{5}{*}{$\begin{array}{c}\mathrm{K}_{\mathrm{c}} \times 10^{10} \\
\left(\mathrm{~N} / \mathrm{m}^{2}\right)\end{array}$} & 0.25784 & 2.0121 & 3.7702 & 5.5324 & 7.2987 & 9.069 \\
\cline { 2 - 7 } & 0.25784 & 2.0946 & 3.9322 & 5.7706 & 7.6098 & 9.4498 \\
\cline { 2 - 7 } & 0.25784 & 2.099 & 3.9408 & 5.7832 & 7.6263 & 9.4701 \\
\cline { 2 - 7 } & 0.25784 & 2.1006 & 3.9439 & 5.7878 & 7.6322 & 9.4773 \\
\cline { 2 - 7 } & 0.25784 & 2.1014 & 3.9455 & 5.7901 & 7.6353 & 9.481 \\
\cline { 2 - 7 } & 0.25784 & 2.1019 & 3.9465 & 5.7915 & 7.6371 & 9.4833 \\
\cline { 2 - 7 } & 0.25784 & 2.1022 & 3.9471 & 5.7925 & 7.6384 & 9.4848 \\
\cline { 2 - 7 } & 0.25784 & 2.1025 & 3.9476 & 5.7932 & 7.6393 & 9.4859 \\
\cline { 2 - 7 } & 0.25784 & 2.1027 & 3.9479 & 5.7937 & 7.6399 & 9.4867 \\
\cline { 2 - 7 } & 0.25784 & 2.1028 & 3.9482 & 5.7941 & 7.6405 & 9.4874 \\
\cline { 2 - 7 } & 0.25784 & 2.1029 & 3.9484 & 5.7944 & 7.6409 & 9.4879 \\
\hline
\end{tabular}

The table 5 shows that at 0 volume fraction, the bulk modulus of composite is equal to the bulk modulus of epoxy matrix, because of complete absence of fibers. It was also observed that with increase in GPL content the bulk modulus increased from $2.5784 \times 10^{9}$ at 0 to $9.069 \times 10^{10}$ at 0.1 volume fraction which is $\sim 34 \%$. The result so obtained show that with small increase in GPL volume the bulk modulus of composite is improved.

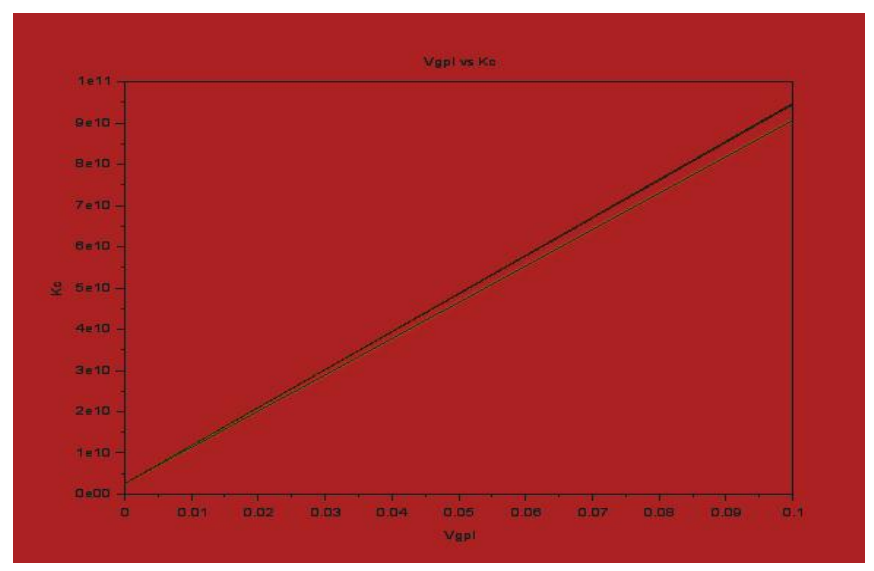

Fig. 4: Graph plotted between $K_{c}$ and $V_{G P L}$

The graph plotted between $G_{c}$ and $V_{G P L}$ show linear increase in bulk modulus for small increase in volume fraction of GPL. The graph starts with a value of $2.5784 \times 10^{9}$ which depicts the absolute correctness of the graph.

Table 6: Variation of $\mathrm{R}_{\mathrm{c}}$ with $\mathrm{V}_{\mathrm{GPL}}$

\begin{tabular}{|c|c|c|c|c|c|c|}
\hline $\mathrm{V}_{\mathrm{GPL}}$ & 0 & 0.02 & 0.04 & 0.06 & 0.08 & 0.1 \\
\hline \multirow{5}{*}{$\begin{array}{c}\mathrm{R}_{\mathrm{c}} \times 10^{3} \\
\left(\mathrm{~kg} / \mathrm{m}^{3}\right)\end{array}$} & 1.0656 & 1.0868 & 1.108 & 1.1292 & 1.1504 & 1.1716 \\
\cline { 2 - 7 } & 1.0656 & 1.0868 & 1.108 & 1.1292 & 1.1504 & 1.1716 \\
\cline { 2 - 7 } & 1.0656 & 1.0868 & 1.108 & 1.1292 & 1.1504 & 1.1716 \\
\cline { 2 - 7 } & 1.0656 & 1.0868 & 1.108 & 1.1292 & 1.1504 & 1.1716 \\
\cline { 2 - 7 } & 1.0656 & 1.0868 & 1.108 & 1.1292 & 1.1504 & 1.1716 \\
\cline { 2 - 7 } & 1.0656 & 1.0868 & 1.108 & 1.1292 & 1.1504 & 1.1716 \\
\cline { 2 - 7 } & 1.0656 & 1.0868 & 1.108 & 1.1292 & 1.1504 & 1.1716 \\
\cline { 2 - 7 } & 1.0656 & 1.0868 & 1.108 & 1.1292 & 1.1504 & 1.1716 \\
\cline { 2 - 7 } & 1.0656 & 1.0868 & 1.108 & 1.1292 & 1.1504 & 1.1716 \\
\cline { 2 - 7 } & 1.0656 & 1.0868 & 1.108 & 1.1292 & 1.1504 & 1.1716 \\
\hline
\end{tabular}

The table 6 shows that at 0 volume fraction the density of composite is equal to the density of epoxy matrix, because of complete absence of fibers. It was also observed that with increase in GPL content the density was increased from $1.0656 \times 10^{3}$ to $1.1716 \times 10^{3} \mathrm{~kg} / \mathrm{m}^{3}$ that is $\sim 10 \%$. The result so obtained show that with small increase in GPL volume the density of composite is increased but not greatly. Hence the lightness of the overall composite is maintained. 


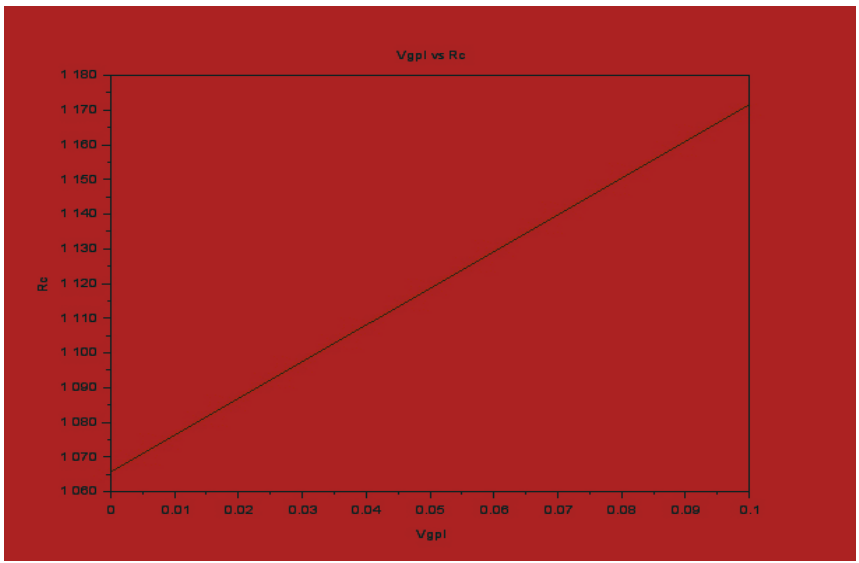

Fig. 5: Graph plotted between $\mathrm{R}_{\mathrm{c}}$ and $\mathrm{V}_{\mathrm{GPL}}$

Graph plotted between $R_{c}$ and $V_{G P L}$ show that there is stable and steady increase of density with increase in volume fraction. The graph starts with a value of $1.0656 \times 10^{3}$ which depicts the absolute correctness of the graph.

\subsection{For load type: Fixed at one end and carrying load at the other end}

The cylindrical shell panel taken for analysis was fixed at one end and free at the other end. A load of $10 \mathrm{~N}$ was provided to the free end in negative $\mathrm{x}$-direction. Mechanical properties from tables 4.1, 4.2, 4.3 and 4.4 were put and analyzed for six different volume fractions of GPL. Static analysis was done by calculating Von-Mises stress and deformation. Some selected maximum and minimum stresses along with deformations are given in table 7 for different volume fractions of GPL.
Table 7: Von-Mises Stress and deformation for different values of $V_{G P L}$ and $R_{c}$ for a shell panel fixed at one end and free at the other $(u=0.33)$

\begin{tabular}{|c|c|c|c|c|c|}
\hline \multirow[t]{2}{*}{$\mathrm{V}_{\mathrm{GPL}}$} & \multirow{2}{*}{$\begin{array}{l}E_{c} \times 10^{4} \\
(\mathrm{MPa})\end{array}$} & \multicolumn{2}{|c|}{ Von-Mises Stress } & Deformation & \multirow{2}{*}{$\begin{array}{l}\mathrm{R}_{\mathrm{c}} \times 10^{-3} \\
\left(\mathrm{~g} / \mathrm{mm}^{3}\right)\end{array}$} \\
\hline & & $\mathrm{S}_{\max }\left(\mathrm{N} / \mathrm{mm}^{2}\right)$ & $\mathrm{S}_{\min }\left(\mathrm{N} / \mathrm{mm}^{2}\right)$ & $\mathrm{D}_{\max }\left(\mathrm{N} / \mathrm{mm}^{2}\right)$ & \\
\hline 0 & 0.263 & 2405.11 & 125.18 & 46268.1 & 1.0656 \\
\hline \multirow[t]{3}{*}{0.02} & 2.0523 & 2405.11 & 125.18 & 5930.08 & \multirow[t]{3}{*}{1.0868} \\
\hline & 2.136 & 2405.11 & 125.18 & 5674.82 & \\
\hline & 2.144 & 2405.11 & 125.18 & 5695.54 & \\
\hline \multirow[t]{3}{*}{0.04} & 3.845 & 2405.11 & 125.18 & 3164.27 & \multirow[t]{3}{*}{1.108} \\
\hline & 4.010 & 2405.11 & 125.18 & 3027.3 & \\
\hline & 4.025 & 2405.11 & 125.18 & 3022.93 & \\
\hline \multirow[t]{3}{*}{0.06} & 5.643 & 2405.11 & 125.18 & 2156.35 & \multirow[t]{3}{*}{1.1292} \\
\hline & 5.886 & 2405.11 & 125.18 & 2067.37 & \\
\hline & 5.909 & 2405.11 & 125.18 & 2059.11 & \\
\hline \multirow[t]{3}{*}{0.08} & 7.444 & 2405.11 & 125.18 & 1634.37 & \multirow[t]{3}{*}{1.1504} \\
\hline & 7.778 & 2405.11 & 125.18 & 1567.7 & \\
\hline & 7.7927 & 2405.11 & 125.18 & 1561.53 & \\
\hline \multirow[t]{3}{*}{0.1} & 9.2504 & 2405.11 & 125.18 & 1315.46 & \multirow[t]{3}{*}{1.1716} \\
\hline & 9.666 & 2405.11 & 125.18 & 1258.78 & \\
\hline & 9.677 & 2405.11 & 125.18 & 1257.38 & \\
\hline
\end{tabular}

The above table shows that for increasing value of $\mathrm{V}_{\mathrm{GPL}}$ and $\mathrm{E}_{\mathrm{c}}$ the maximum and minimum stress values remains constant. The deformation value decreases $\sim 97 \%$ with increase in $V_{\mathrm{GPL}}$ and $\mathrm{E}_{\mathrm{c}}$.

\subsection{Simulation results in ANSYS for cylindrical shell panel fixed at one end and free at the other:}

Illustrations in figure 6 and 7 are ANSYS simulation results for shell panel fixed at one end and carrying load at the free end. The results depict the variation of maximum and minimum stress and deformation in the shell panel for varying $\mathrm{V}_{\mathrm{GPL}}$.

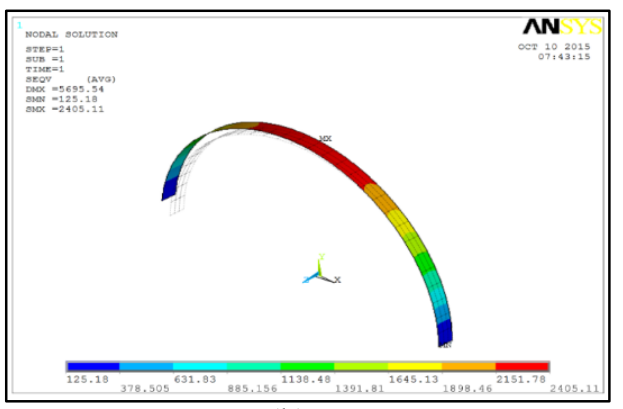

(b)

(a)

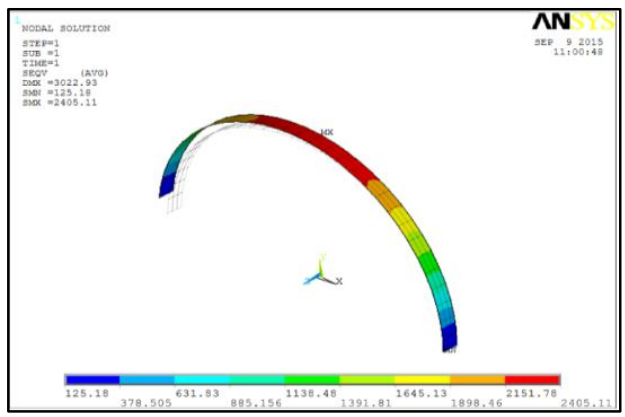

(c)

Fig. 6 (a), (b), (c): Maximum and minimum stress, deformation of the shell panel fixed at one end and free at the other for $\mathrm{V}_{\mathrm{GPL}}$ at $0,0.02,0.04$ respectively. 
Figure 6(a) illustrates at $0, \mathrm{~V}_{\mathrm{GPL}}$, with elastic modulus and density of $2630 \mathrm{MPa}$ and $1.0656 \times 10^{3} \mathrm{~g} / \mathrm{mm}^{3}$ the maximum Von-Mises stress was found to be $2405.11 \mathrm{~N} / \mathrm{mm}^{2}$ and the deformation was found to be $46268.1 \mathrm{~N} / \mathrm{mm}^{2}$. Similarly Figure 6 (b) illustrates at $0.02 \mathrm{~V}_{\mathrm{GPL}}$, with elastic modulus and density of $21365 \mathrm{MPa}$ and $1.0868 \times 10^{3} \mathrm{~g} / \mathrm{mm}^{3}$ the maximum
Von-Mises stress was found to be $2405.11 \mathrm{~N} / \mathrm{mm}^{2}$ and the deformation was found to be $5695.54 \mathrm{~N} / \mathrm{mm}^{2}$. In figure 6(c) the maximum Von-Mises stress was found to be 2405.11 $\mathrm{N} / \mathrm{mm}^{2}$ and decrease in deformation was found to be 3022.93 $\mathrm{N} / \mathrm{mm}^{2}$ at 0.04 of $\mathrm{V}_{\mathrm{GPL}}$ with elastic modulus and density of $40254 \mathrm{MPa}$ and $1.108 \times 10^{3} \mathrm{~g} / \mathrm{mm}^{3}$.

\subsection{Simulation results in ANSYS for cylindrical shell panel fixed at one end and free at the other:}

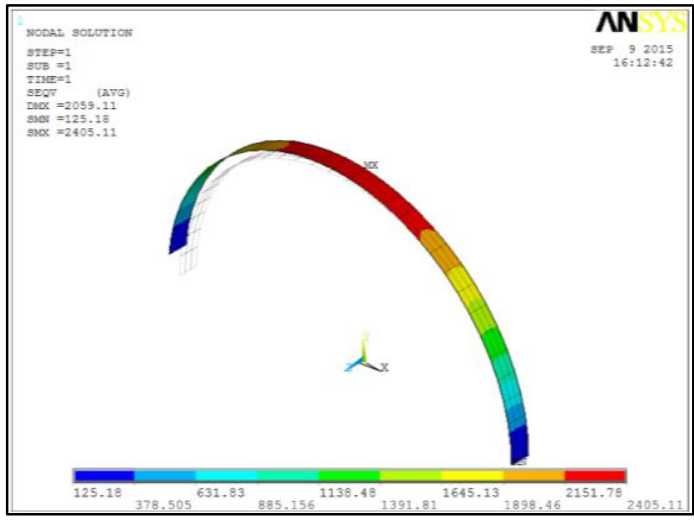

(a)

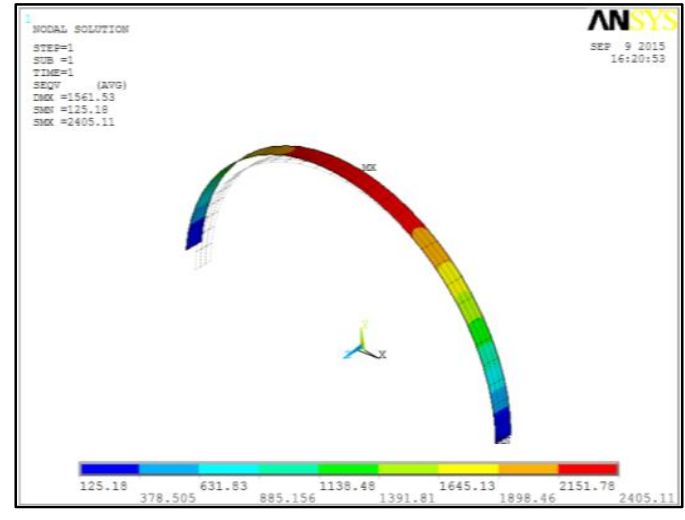

(b)

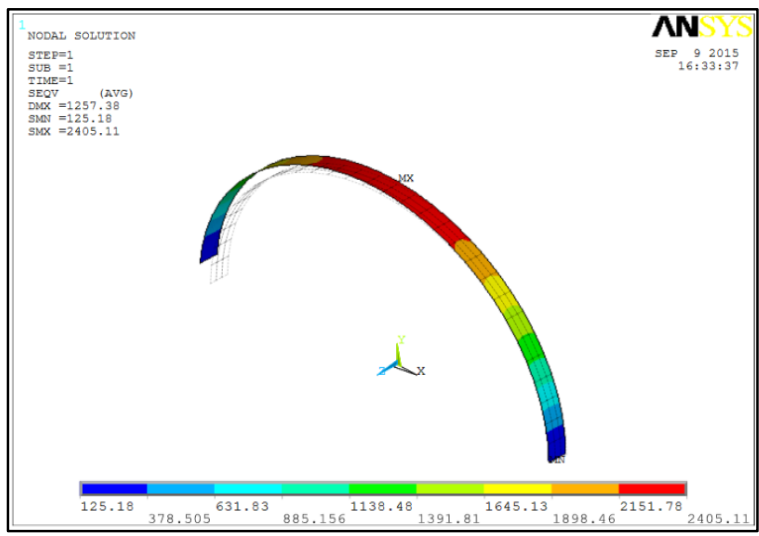

(b)

Fig. 7 (a), (b), (c): Maximum and minimum stress, deformation of the shell panel fixed at one end and free at the other for $\mathrm{V}_{\mathrm{GPL}}$ at $0.06,0.08,0.1$ respectively.

Figure 4.6 (a) shows that at 0.06 of $\mathrm{V}_{\mathrm{GPL}}$ with elastic modulus and density of $59096 \mathrm{MPa}$ and $1.1292 \times 10^{3} \mathrm{~g} / \mathrm{mm}^{3}$ the maximum Von-Mises stress remains same as previous value of $2405.11 \mathrm{~N} / \mathrm{mm}^{2}$ and the deformation was found to be decreased from $3022.93 \mathrm{~N} / \mathrm{mm}^{2}$ to $2059.11 \mathrm{~N} / \mathrm{mm}^{2}$. Further figure 4.6 (b) and (c) illustrates that at 0.08 and 0.1 of $V_{\mathrm{GPL}}$ with elastic modulus and density varying from 77927-96777 $\mathrm{MPa}$ and $1.1504 \times 10^{3}-1.1716 \times 10^{3} \mathrm{~g} / \mathrm{mm}^{3}$ the maximum VonMises stress was found to be constant $\left(2405.11 \mathrm{~N} / \mathrm{mm}^{2}\right)$ and the deformation was found to be decreasing with values $1561.53 \mathrm{~N} / \mathrm{mm}^{2}$ and $1257.38 \mathrm{~N} / \mathrm{mm}^{2}$.

\subsection{For load type: Fixed at both the ends and carrying a uniformly distributed load over it}

The cylindrical shell panel taken for analysis was fixed at both the ends and a uniformly distributed load of $10 \mathrm{~N}$ was provided in negative $\mathrm{y}$-direction. Mechanical properties from tables $4.1,4.2,4.3$ and 4.4 were put and analyzed for six different volume fractions of GPL. Static analysis was done by calculating Von-Mises stress and deformation. Some selected maximum and minimum stresses along with deformations are given in table 4.6 for different volume fractions of GPL. 
International Journal of Applied Engineering Research ISSN 0973-4562 Volume 14, Number 1 (2019) pp. 69-78

(C) Research India Publications. https://dx.doi.org/10.37622/IJAER/14.1.2019.69-78

Table 8: Von-Mises Stress and deformation for different values of $V_{G P L}$ and $R_{c}$ for a shell panel fixed at both the ends $(v=0.33)$

\begin{tabular}{|c|c|c|c|c|c|}
\hline \multirow[t]{2}{*}{$\mathrm{V}_{\mathrm{GPL}}$} & \multirow[t]{2}{*}{$\mathrm{E}_{\mathrm{c}} \times 10^{4}(\mathrm{MPa})$} & \multicolumn{2}{|c|}{ Von-Mises Stress } & \multirow{2}{*}{$\begin{array}{c}\text { Deformation } \\
\mathrm{D}_{\max }\left(\mathrm{N} / \mathrm{mm}^{2}\right)\end{array}$} & \multirow[t]{2}{*}{$\mathrm{R}_{\mathrm{c}} \times 10^{-3}\left(\mathrm{~g} / \mathrm{mm}^{3}\right)$} \\
\hline & & $\mathrm{S}_{\max }\left(\mathrm{N} / \mathrm{mm}^{2}\right)$ & $\mathrm{S}_{\min }\left(\mathrm{N} / \mathrm{mm}^{2}\right)$ & & \\
\hline 0 & 0.263 & 1751.94 & 24.93 & 150.19 & 1.0656 \\
\hline \multirow[t]{3}{*}{0.02} & 2.0523 & 1751.94 & 24.93 & 134.60 & \multirow[t]{3}{*}{1.0868} \\
\hline & 2.136 & 1751.94 & 24.93 & 128.8 & \\
\hline & 2.144 & 1751.94 & 24.93 & 129.27 & \\
\hline \multirow[t]{3}{*}{0.04} & 3.845 & 1751.94 & 24.93 & 71.82 & \multirow[t]{3}{*}{1.108} \\
\hline & 4.010 & 1751.94 & 24.93 & 68.71 & \\
\hline & 4.025 & 1751.94 & 24.93 & 68.614 & \\
\hline \multirow[t]{3}{*}{0.06} & 5.643 & 1751.94 & 24.93 & 48.94 & \multirow[t]{3}{*}{1.1292} \\
\hline & 5.886 & 1751.94 & 24.93 & 46.925 & \\
\hline & 5.909 & 1751.94 & 24.93 & 46.73 & \\
\hline \multirow[t]{3}{*}{0.08} & 7.444 & 1751.94 & 24.93 & 37.103 & \multirow[t]{3}{*}{1.1504} \\
\hline & 7.778 & 1751.94 & 24.93 & 35.583 & \\
\hline & 7.7927 & 1751.94 & 24.93 & 35.443 & \\
\hline \multirow[t]{3}{*}{0.1} & 9.2504 & 1751.94 & 24.93 & 29.8582 & \multirow[t]{3}{*}{1.1716} \\
\hline & 9.666 & 1751.94 & 24.93 & 28.571 & \\
\hline & 9.677 & 1751.94 & 24.93 & 28.53 & \\
\hline
\end{tabular}

The table above shows that for a cylindrical shell panel fixed at both the ends, with increase in $\mathrm{V}_{\mathrm{GPL}}$ and $\mathrm{E}_{\mathrm{c}}$ value the maximum and minimum stress value remains constant. The deformation so found decreases for the respective values of $\mathrm{V}_{\mathrm{GPL}}$ and $\mathrm{E}_{\mathrm{c}}$, from 150.19 to $28.53 \mathrm{~N} / \mathrm{mm}^{2}$.

\subsection{Simulation results in ANSYS for cylindrical shell panel fixed at both ends:}

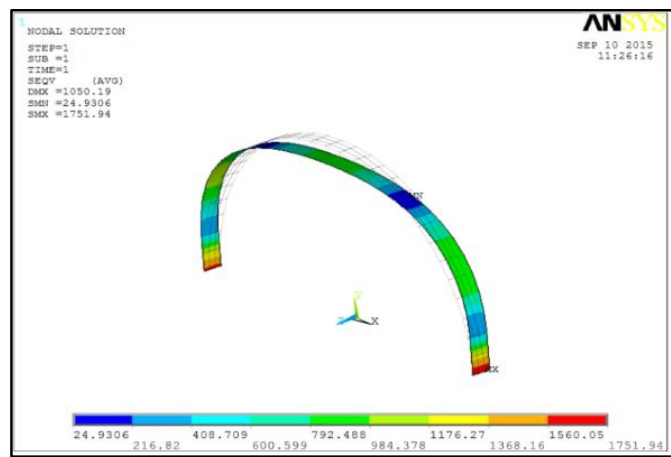

(a)

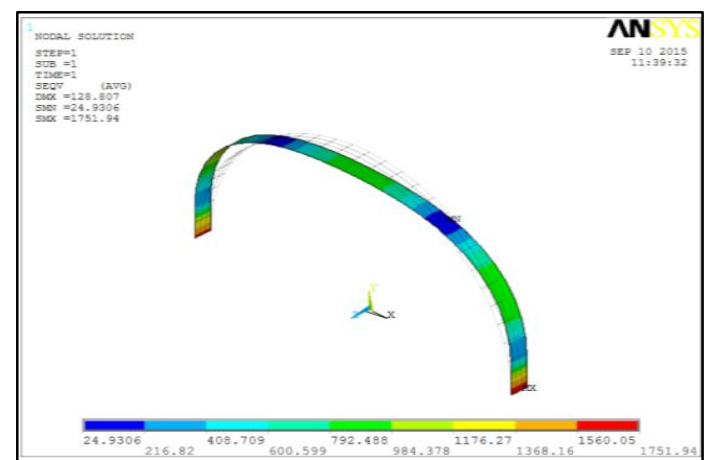

(b)

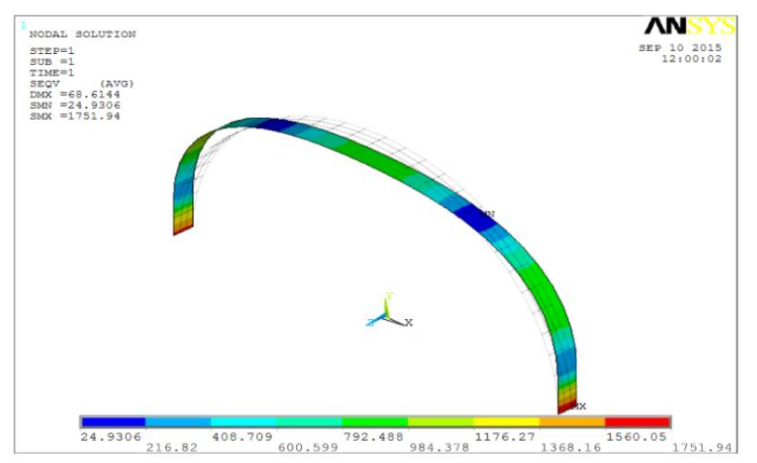

(c)

Fig. 8 (a), (b), (c): Maximum and minimum stress, deformation of the shell panel fixed at both ends for $\mathrm{V}_{\mathrm{GPL}}$ at $0,0.02$, and 0.04 respectively. 


\subsection{Simulation results in ANSYS for cylindrical shell panel fixed at both ends:}

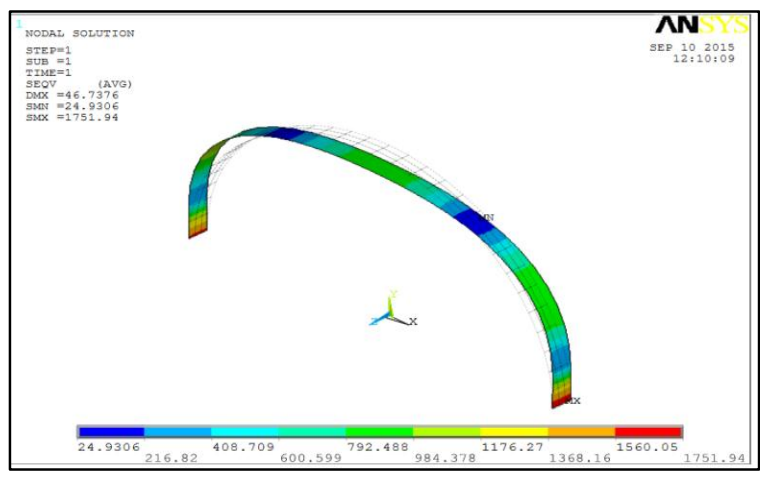

(a)

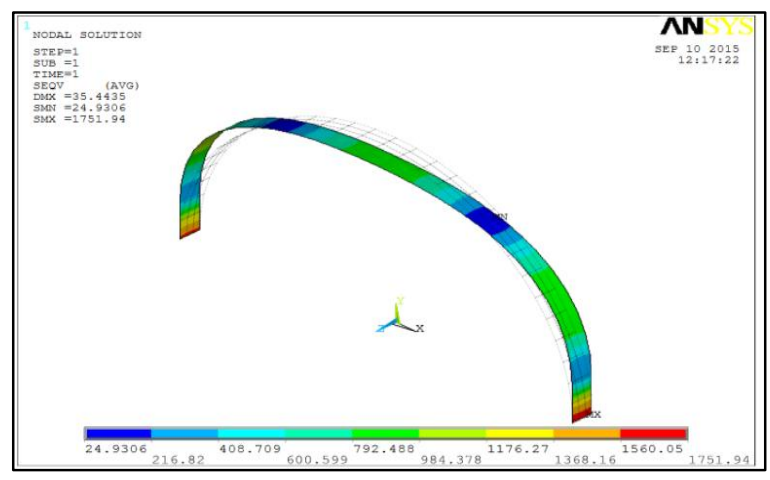

(b)

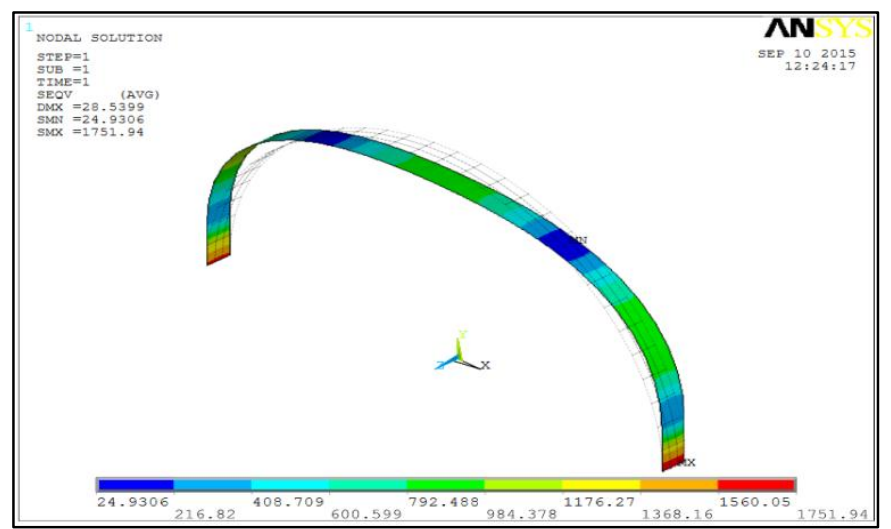

Fig. 9 (a), (b), (c): Maximum and minimum stress, deformation of the shell panel fixed at one end and free at the other for $\mathrm{V}_{\mathrm{GPL}}$ at $0.06,0.08,0.1$ respectively.

Figure 9 (a) depicts at 0.06 of $\mathrm{V}_{\mathrm{GPL}}$ with elastic modulus and density of $59096 \mathrm{MPa}$ and $1.1292 \times 10^{3} \mathrm{~g} / \mathrm{mm}^{3}$ respectively, the maximum Von-Mises stress was found to be $1751.94 \mathrm{~N} / \mathrm{mm}^{2}$ and the deformation was still reduced with a value of 46.73 $\mathrm{N} / \mathrm{mm}^{2}$. Figure 9(b) and 9(c) illustrates that at 0.08 and 0.1 of $\mathrm{V}_{\mathrm{GPL}}$, with increase in elastic modulus and density from $77927-96777 \mathrm{MPa}$ and $1.1504 \times 10^{3}-1.1716 \times 10^{3} \mathrm{~g} / \mathrm{mm}^{3}$ the maximum Von-Mises stress was found to be constant as previous $1751.94 \mathrm{~N} / \mathrm{mm}^{2}$ with decrease in deformation value $35.443-28.53 \mathrm{~N} / \mathrm{mm}^{2}$.

\subsection{Variation of Ec, $S_{\max }$ and $D_{\max }$ with respect to $V_{G P L}$ for shell panel fixed at one end}

The variation of young's modulus, maximum stress and deformation with increase in percentage of GPL volume fraction is shown graphically for better understanding. Figure 4.9 and 4.10 shows these variations for the two type of loading conditions in the shell panel.

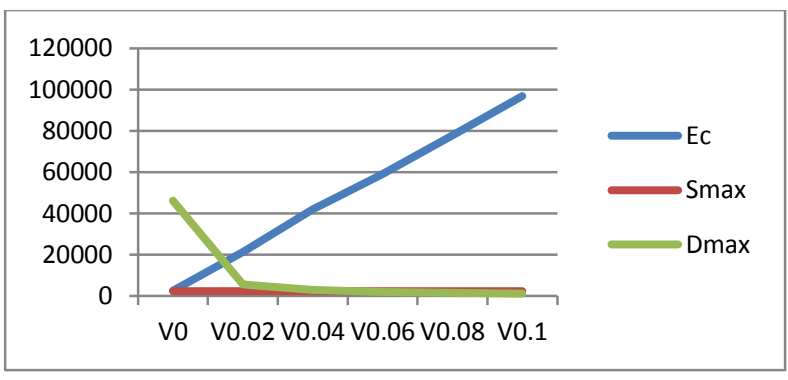

Fig. 10: Variation of $E_{c}, S_{\max }$ and $D_{\max }$ with increase in volume fraction of GPL for shell structure fixed at one end and free at the other end with load at free end.

The above graph shows the variation of $E_{c}, S_{\max }$ and $D_{\max }$ with respect to change in $\mathrm{V}_{\mathrm{GPL}} \%$ for loading type fixed at one end and carrying load of $10 \mathrm{~N}$ at the other end in negative $\mathrm{x}$ direction. The graph indicates a very large increase of young's modulus as compared to the changes in stress and deformation which means overall increase in mechanical property of composite. The figure shows that the deformation is very less when load is provided, making the composite suitable for many structural applications. 
3.9 Variation of Ec, $S_{\max }$ and $D_{\max }$ with respect to $V_{G P L}$ for shell panel fixed at both ends

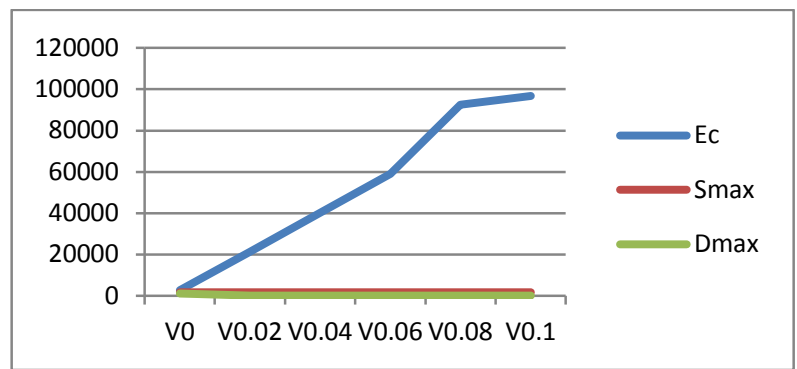

Fig 11: The variation of $E_{c}, S_{\max }$ and $D_{\max }$ with increase in volume fraction of GPL for shell structure fixed at both the ends with load provided on top.

The above graph shows the variation of $E_{c}, S_{\max }$ and $D_{\max }$ with respect to change in $\mathrm{V}_{\mathrm{GPL}}$ for loading type fixed at both the ends and carrying load of $10 \mathrm{~N}$ in negative y-direction. The graph indicates a very large increase of young's modulus as compared to the changes in stress and deformation which means overall increase in mechanical property of composite. The figure shows that the deformation is very less when load is provided making the composite suitable for many structural applications.

\section{CONCLUSION}

In summary, the study shows the following:

- At low nano-filler content of Graphene platelets the mechanical properties such as elastic modulus, shear modulus, bulk modulus and density of composite were increased.

- $\quad$ The elastic modulus was increased from 2630 to 96777 $\mathrm{MPa}$ and that of shear modulus and bulk modulus was increased from $9.8872 \times 10^{8}$ to $3.4776 \times 10^{10} \mathrm{MPa}$ and $2.5784 \times 10^{9}$ to $9.069 \times 10^{10} \mathrm{MPa}$ respectively.

- $\quad 40 \%$ increase in elastic modulus and $34 \%$ increase of both shear and bulk modulus depicts that the composite material so formed was more elastic, less prone to deformation and less change in volume respectively.

- The density so increased that is from $1.0656 \times 10^{-3}$ to $1.1716 \times 10^{-3} \mathrm{~g} / \mathrm{mm}^{3}$. The $\sim 10 \%$ increase was not that large which states that the lightness of the composite was maintained.

- The properties obtained were analyzed by using a powerful finite element tool for different loading conditions.

- $\quad$ For first loading condition; shell panel fixed at one end and carrying load of $10 \mathrm{~N}$ at the free end it was observed that stress value remains constant $2405.11 \mathrm{~N} / \mathrm{mm}^{2}$ and deformation decreases from 46268.1 to $1257.38 \mathrm{~N} / \mathrm{mm}^{2}$ with increase in $\mathrm{V}_{\mathrm{GPL}}(0-0.1)$.

- For second loading condition; shell panel fixed at both ends and carrying load of $10 \mathrm{~N}$ vertically it was observed that stress value remains constant (1751.94
$\mathrm{N} / \mathrm{mm}^{2}$ ) and deformation value decreases from 1050.19 to $28.53 \mathrm{~N} / \mathrm{mm}^{2}$ respectively.

\section{ACKNOWLEDGMENTS}

The Authors would like to thank all technical assistant of central workshop and Principal of Government College of Engineering Kalahandi, Bhawanipatna, Odisha for helping in successful completion of this research work.

\section{REFERENCES}

[1] Wu, H., Kitipornchai, S., Ke, L. L. and Yang, J., 2017, "Static analysis of functionally graded graphene nanocomposite beams under thermo-electromechanical loading", Proceedings of 8th International Conference on Computational Methods (ICCM2017).

[2] Hussain, F., Hojjati, M., Okamoto, M. and Gorga, R. E., 2006, "Polymer-matrix Nanocomposites, Processing, Manufacturing, and Application: An Overview", Journal of Composite Materials, 40(17), pp. 1511-1575.

[3] Song, M., Yang, J. and Kitipornchai, S., 2018, "Bending and buckling analyses of functionally graded polymer composite plates reinforced with graphene nanoplatelets", S., Composites Part B: Engineering, 134, pp. 106-113.

[4] Song, M., Yang, J., Kitipornchai, S. and Zhu, W., 2017, "Buckling and postbuckling of biaxially compressed functionally graded multilayer graphene nanoplatelet reinforced polymer composite plates", International Journal of Mechanical Sciences, 131-132, pp. 345-355.

[5] Wu, H., Yang, J. and Kitipornchai, S., 2017, "Dynamic instability of functionally graded multilayer graphene nanocomposite beams in thermal environment", Composite Structures, 162, pp. 244-254.

[6] Mekala, N. R., Schmidt, R. and Schröder, K. U., 2017, "Modelling and Analysis of Piezolaminated Functionally Graded Polymer Composite Structures Reinforced with Graphene Nanoplatelets under Strong Electroelastic Fields" Applied Mechanics and Materials, 875, pp. 3-8.

[7] Feng, C. Kitipornchai, S. and Yang, J., 2017, "Nonlinear free vibration of functionally graded polymer composite beams reinforced with graphene nanoplatelets (GPLs)", Engineering Structures, 140, pp. 110-119.

[8] Wang, M., Hu, N., Zhou, L. and Yan, C., 2015, "Enhanced interfacial thermal transport across graphene-polymer interfaces by grafting polymer chains", Carbon, 85, pp. 414-421.

[9] Feng, C., Kitipornchai, S. and Yang, J., 2017, "Nonlinear bending of polymer nanocomposite beams reinforced with non-uniformly distributed graphene platelets (GPLs)" Composites Part B, 110, pp. 132-140. 
International Journal of Applied Engineering Research ISSN 0973-4562 Volume 14, Number 1 (2019) pp. 69-78

(C) Research India Publications. https://dx.doi.org/10.37622/IJAER/14.1.2019.69-78

[10] Sun, R. Li, L., Feng, C., Kitipornchai, S. and Yang, J., 2018, "Tensile behavior of polymer nanocomposite reinforced with graphene containing defects", European Polymer Journal, 98, pp. 475-482.

[11] Zhao, Z., Feng, C., Wang, Y. and Yang, J., 2017, "Bending and vibration analysis of functionally graded trapezoidal nanocomposite plates reinforced with graphene nanoplatelets (GPLs)", Composite Structures, 180, pp. 799-808.

[12] Song, M., Kitipornchaia, S. and Yang, J. 2017, "Free and forced vibrations of functionally graded polymer composite plates reinforced with graphene nanoplatelets", Composite Structures, 159, pp. 579588.

[13] Wang, Y., Feng, C., Zhao, Z. and Yang, J., 2018, "Eigenvalue buckling of functionally graded cylindrical shells reinforced with graphene platelets (GPL)", Composite Structures, 202, pp. 38-46. 